\title{
The Neurosurgical Management of Peroneal Nerve Injury: An Experience of 14 Cases
}

\author{
Simas RT ${ }^{1,2}$, Caires ACV', Monteiro PIP ${ }^{1,2}$, Dantas \\ $F^{1,2}$ and Dantas FLR ${ }^{1,3 *}$ \\ ${ }^{1}$ Department of Neurosurgery, Biocor Instituto, Nova \\ Lima, Minas Gerais, Brazil \\ ${ }^{2}$ Post-Graduation, Faculdade de Ciências Médicas de \\ Minas Gerais - Feluma, Belo Horizonte, Minas Gerais, \\ Brazil \\ 3Post-Graduation, Instituto de Assistência Médica ao \\ Servidor Público Estadual de São Paulo - IAMSPE, São \\ Paulo, São Paulo, Brazil \\ *Corresponding author: Dantas FLR, Department of \\ Neurosurgery, Biocor Instituto, Alameda Oscar Niemeyer, \\ 217, Nova Lima, Minas Gerais, Brazil
}

Received: J une 14, 2021; Accepted: J uly 13, 2021; Published: J uly 20, 2021

\begin{abstract}
Objectives: To describe the neurosurgical technical nuances of peroneal nerve injury management and to analyze the outcomes of patients diagnosed with peroneal nerve injury operated on at a single institution.
\end{abstract}

Methods: Fourteen patients, all with electroneuromyography confirmation of peroneal nerve injury, were retrospectively analyzed. The variables analyzed included patient demographic characteristics, etiology of the lesion, preoperative neurological status, location of the lesion, perioperative findings, surgical technique, complications, and neurological status six months postoperatively.

Results: Traumatic injury was the most common cause of peroneal nerve injury, accounting for $64.27 \%$ of cases. Concerning surgical technique, neurolysis was the preferred technique in most cases. Isolated neurolysis was performed in $50 \%$ of the cases, neurolysis combined with graft in $7.14 \%$, and neurolysis combined with ganglion cyst excision in $21.43 \%$. In our study, surgical treatment led to improvement in foot strength, with statistical relevance, in both sexes. Only one complication was observed.

Conclusions: Surgical exploration and repair of peroneal nerve injuries achieved good results in this series, with functional improvement of the analyzed patients in both sexes. When appropriate, surgical repair can lead to favorable outcome and early surgery can be a therapeutic strategy in selected cases.

Keywords: Peroneal nerve; Nerve graft; Micro neurolysis; Compression; Neuropathy

\section{Introduction}

Peroneal nerve injury is the most frequent pathology of the lower limbs, and accounts for about $15-20 \%$ of all peripheral nerve lesions [1]. The peroneal nerve arises from the roots of L4-S2 and is a lateral division of the sciatic nerve.

The sciatic nerve divides into the tibial and common peroneal nerves in the apex of the popliteal fossa. The common peroneal nerve subsequently travels around the fibular neck and then passes between the two heads of the peroneus longus muscle. The common peroneal nerve then divides into both the superficial and deep branches $[2,3]$.

The location of the peroneal nerve, which is superficially located over the fibular head, is responsible for its vulnerability $[1,4,5]$. The peroneal nerve seems particularly prone to injury from motor vehicle accidents, gunshot wounds, iatrogenic accidents, and sport injuries [1]. Beyond that the compression of the peroneal nerve could be induced by a ganglion cyst, cysts of the lateral meniscus, or a tumor of the fibula head $[2,6,7]$.

The peroneal nerve injury result in a variety of symptoms, including foot drop due to paralysis of the affected musculature, as well as sensory disturbances over the lateral surface of the lower extremity or the dorsum of the foot [2].

The diagnosis depends on understanding the anatomy of the peroneal nerve and on clinical findings. The literature recommends surgical decompression of the common peroneal nerve in some cases, but surgical results are rarely described. Adequate surgical repair is responsible for the physiological maintenance of gait biomechanics [2].

Our objectives were to describe the neurosurgical technical nuances of peroneal nerve injury management and to analyze the outcomes of patients diagnosed with peroneal nerve injury and operated on by a single neurosurgeon at a private institution.

\section{Materials and Methods}

We performed a retrospective analysis with data collection from the medical records of patients diagnosed with peroneal nerve injury surgically treated by a single neurosurgeon at a single private institution, from 2000 to 2018 . Thirty medical records were analyzed, and fourteen patients were included in the analysis. The inclusion criteria were patients $>18$ years old, peroneal nerve injury confirmed by electroneuromyography, patients whose medical records showed preoperative neurological status, and patients with a minimum follow-up of 6 months. Patients $<18$ years old, without electroneuromyographic studies, or patients with a follow-up of $<6$ months were not included in the study.

The variables analyzed were demographic characteristics, etiology of the lesion, preoperative neurological status, strength graduation (Table 1) [8], time between symptoms and surgery, location of lesion, perioperative finding, surgical technique (suture, neurolysis, and graft), complications, and neurological status 6 months after surgery. 
Table 1: Muscle Grading System for Peroneal Nerve Injuries.

\begin{tabular}{|c|l|}
\hline Grade & \multicolumn{1}{|c|}{ Indications } \\
\hline 0 & No palpable muscle contraction. \\
\hline 1 & Palpable contraction of the peronei or anterior tibial muscles. \\
\hline 2 & Peronei or anterior tibial muscles contract against gravity. \\
\hline 3 & $\begin{array}{l}\text { Peronei or anterior tibial muscles contract against gravity and give } \\
\text { some resistance. }\end{array}$ \\
\hline 4 & $\begin{array}{l}\text { Peronei and anterior tibial muscles contract against moderate } \\
\text { resistance. }\end{array}$ \\
\hline 5 & Peronei and anterior tibial muscles contract against great resistance. \\
\hline
\end{tabular}

Kim et al. 2004 [8]

Table 2: Influence of sex on etiology.

\begin{tabular}{|c|c|c|c|}
\hline \multirow{2}{*}{ Etiology } & \multicolumn{2}{|c|}{ Sex } & \multirow{2}{*}{ Total } \\
\cline { 2 - 4 } & Female & Male & \\
\hline Spontaneous & $25 \%(1 / 4)$ & $0 \%(0 / 10)$ & $7.14 \%(1 / 14)$ \\
\hline Traumatic & $50 \%(2 / 4)$ & $70 \%(7 / 10)$ & $64.29 \%(9 / 14)$ \\
\hline Tumoral & $25 \%(1 / 4)$ & $20 \%(2 / 10)$ & $21.43 \%(3 / 14)$ \\
\hline Mixed & $0 \%(0 / 4)$ & $10 \%(1 / 10)$ & $7.14 \%(1 / 14)$ \\
\hline
\end{tabular}

The proportional data was presented with a descriptive analysis and all the non-parametric data was compared with the data from the Wilcoxon test; any value $<0.05$ was considered statistically significant. The utilized software was the Statistical Analyses System (SAS).

\section{Results}

Fourteen patients were analyzed, of which four were female and ten male. Table 2 demonstrates the influence of sex on etiology, especially in traumatic injuries, with $70 \%$ occurring in men and $50 \%$ in women. Tumoral lesions occurred in $25 \%$ of cases among female patients and in $20 \%$ among male patients. Mixed injuries were seen only in men with a prevalence of $10 \%$.

Regardless of diagnose, $50 \%$ of the patients were diagnosed with traumatic neuroma (Figure 1) and $21.43 \%$ with ganglion cyst (Figure 2), as shown in Table 3.

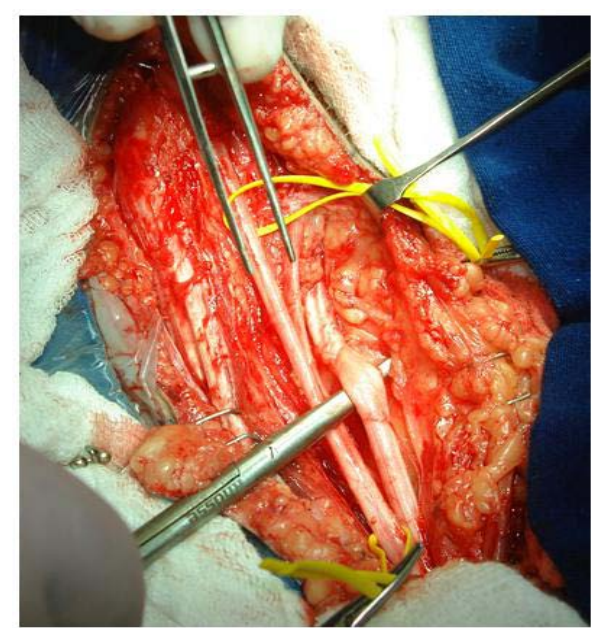

Figure 1: A 64-year-old patient with traumatic neuroma, victim of car trauma with injury of the left common peroneal nerve. At admission, the patient presented with grade 0 strength on his left foot. He underwent neurolysis 3 months after trauma and evolved with complete strength recovery at 6-months follow-up.
Table 3: Influence of sex on preoperative diagnosis.

\begin{tabular}{|c|c|c|c|}
\hline \multirow{2}{*}{ Diagnosis } & \multicolumn{2}{|c|}{ Sex } & \multirow{2}{*}{ Total } \\
\cline { 2 - 3 } & Female & Male & \\
\hline Fibrosis and Stenosis & $0 \%(0 / 4)$ & $10 \%(1 / 10)$ & $7.14 \%(1 / 14)$ \\
\hline Ganglion Cyst & $0 \%(0 / 4)$ & $30 \%(3 / 10)$ & $21.43 \%(3 / 14)$ \\
\hline Traumatic Neuroma & $50 \%(2 / 4)$ & $50 \%(5 / 10)$ & $50 \%(7 / 14)$ \\
\hline Schwannoma of Left Popliteal Fossa & $25 \%(1 / 4)$ & $0 \%(0 / 10)$ & $7.14 \%(1 / 14)$ \\
\hline Pale Looking Nerve & $0 \%(0 / 4)$ & $10 \%(1 / 10)$ & $7.14 \%(1 / 14)$ \\
\hline Fibrosis & $25 \%(1 / 4)$ & $0 \%(0 / 10)$ & $7.14 \%(1 / 14)$ \\
\hline
\end{tabular}

Table 4: Influence of sex on the injury site.

\begin{tabular}{|c|c|c|c|}
\hline \multirow{2}{*}{ Injury Site } & \multicolumn{2}{|c|}{ Sex } & \multirow{2}{*}{ Total } \\
\cline { 2 - 3 } & Female & Male & \\
\hline Left Common Peroneal & $50 \%(2 / 4)$ & $20 \%(2 / 10)$ & $28.57 \%(4 / 14)$ \\
\hline Right Common Peroneal & $25 \%(1 / 4)$ & $40 \%(4 / 10)$ & $35.71 \%(5 / 14)$ \\
\hline Right and Left Common Peroneal & $25 \%(1 / 4)$ & $0 \%(0 / 10)$ & $7.14 \%(1 / 14)$ \\
\hline Right Superficial Peroneal & $0 \%(0 / 4)$ & $10 \%(1 / 10)$ & $7.14 \%(1 / 14)$ \\
\hline $\begin{array}{c}\text { Common Sciatic, Tibial, and Peroneal } \\
\text { Rights }\end{array}$ & $0 \%(0 / 4)$ & $20 \%(2 / 10)$ & $14.29 \%(2 / 14)$ \\
\hline Left Common Sciatic and Peroneal & $0 \%(0 / 4)$ & $10 \%(1 / 10)$ & $7.14 \%(1 / 14)$ \\
\hline
\end{tabular}

Table 5: Operative technique used according to sex.

\begin{tabular}{|c|c|c|c|}
\hline \multirow{2}{*}{ Technique } & \multicolumn{2}{|c|}{ Sex } & \multirow{2}{*}{ Total } \\
\cline { 2 - 3 } & Female & Male & \\
\hline Graft & $25 \%(1 / 4)$ & $10 \%(1 / 10)$ & $14.29 \%(2 / 14)$ \\
\hline Neurolysis & $50 \%(2 / 4)$ & $50 \%(5 / 10)$ & $50.00 \%(7 / 14)$ \\
\hline Neurolysis and Graft & $0 \%(0 / 4)$ & $10 \%(1 / 10)$ & $7.14 \%(1 / 14)$ \\
\hline Exeresis & $25 \%(1 / 4)$ & $0 \%(0 / 10)$ & $7.14 \%(1 / 14)$ \\
\hline $\begin{array}{c}\text { Ganglion Cyst Excision and } \\
\text { Neurolysis }\end{array}$ & $0 \%(0 / 4)$ & $30 \%(3 / 10)$ & $21.43 \%(3 / 14)$ \\
\hline
\end{tabular}

The most common injury observed in our series was isolated right common peroneal injury (35.71\%), followed by isolated left common peroneal injury (28.75\%), and then by joint nerve injury right sciatic, tibial and peroneal (14.29\%), as shown in Table 4.

In our analysis, $42.85 \%$ of patients (6/14) underwent surgical treatment at less than 3 months after symptom onset (interval ranging from 7 days to 60 days), and $57.14 \%$ (8/14) underwent treatment 3 months after symptom onset (3 to 9 months). After analysis of patients who had complete strength recovery after 6 months of follow-up ( $42.85 \% ; 6 / 14), 50 \%$ of these ( $3 / 6$ patients) were approached within 3 months of symptom onset; all these patients showed blunt injuries and neurolysis was the technique performed, whether mixed or isolated.

The most commonly performed surgical technique was neurolysis, either isolated (50\%), combined with a graft (7.14\%), or combined with ganglion cyst excision (21.43\%). Isolated graft (Figure 3 ) was performed in $14.29 \%$ of the cases and combined with other techniques in $7.14 \%$ of the cases (Table 5). In 3 cases in which the graft technique was used, all patients had grade 0 strength in the preoperative period and the results obtained at follow-up were little or no improvement in strength (33\% Grade 0, 33\% Grade 1,33\% Grade 3 at 6 months postoperatively). 


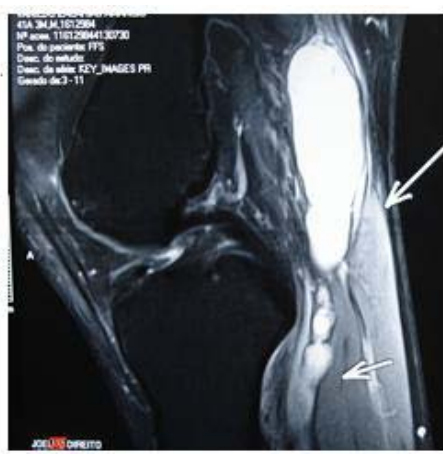

A

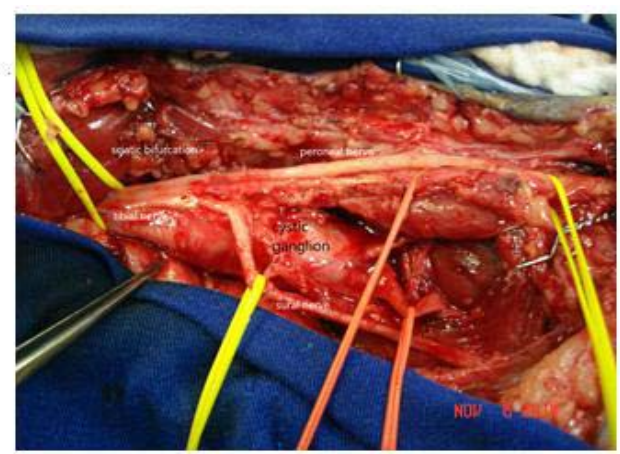

B

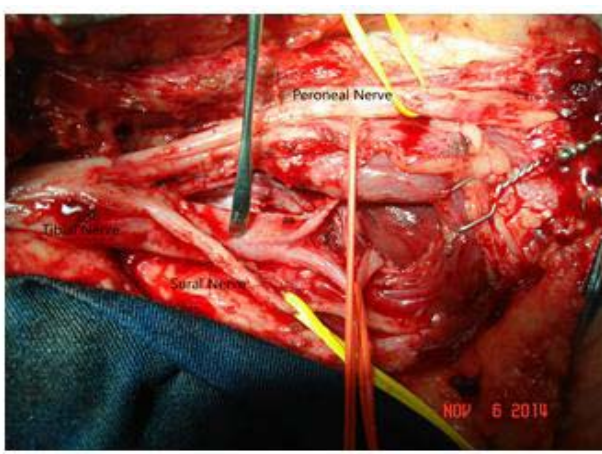

Figure 2: A 41-year-old patient presented with grade 0 strength and was diagnosed with ganglion cyst on knee MRI (A). He underwent excision of the lesion (B,C) and neurolysis 2 months after the onset of symptoms, evolving with partial strength recovery (grade 3 ). In the late follow-up, he maintained hypoesthesia of the foot.

Table 6: Influence of sex on time from symptom onset to surgery, preoperative strength and at 6 months after surgery.

\begin{tabular}{|c|c|c|c|c|c|c|}
\hline \multirow{2}{*}{ Variable } & \multicolumn{3}{|c|}{ Female } & \multicolumn{3}{|c|}{ Male } \\
\hline & Mean \pm SD & Median & Variation & Mean \pm SD & Median & Variation \\
\hline Age (years) & $30.0 \pm 10.8$ & 29.5 & $19-42$ & $40.0 \pm 15.11$ & 40 & $12-64$ \\
\hline Time from symptoms to surgery (days) & $96.75 \pm 96.28$ & 100 & $7-180$ & $91.50 \pm 67.25^{\mathrm{a}}$ & 90 & $15-270$ \\
\hline Preoperative strength & $1.25 \pm 2.50^{\mathrm{Aa}}$ & 0 & $0-5.0$ & $0.80 \pm 1.61^{\mathrm{Aa}}$ & 0 & $0.0-5.0$ \\
\hline Strength 6 months after surgery & $3.75 \pm 1.50^{\mathrm{Ba}}$ & 4 & $2.0-5.0$ & $3.00 \pm 2.06^{\mathrm{Ba}}$ & 3 & $0.0-5.0$ \\
\hline
\end{tabular}

Means followed by different letters, lower case in the row and upper case in the column, differ ( $p<0.05$; Wilcoxon test).

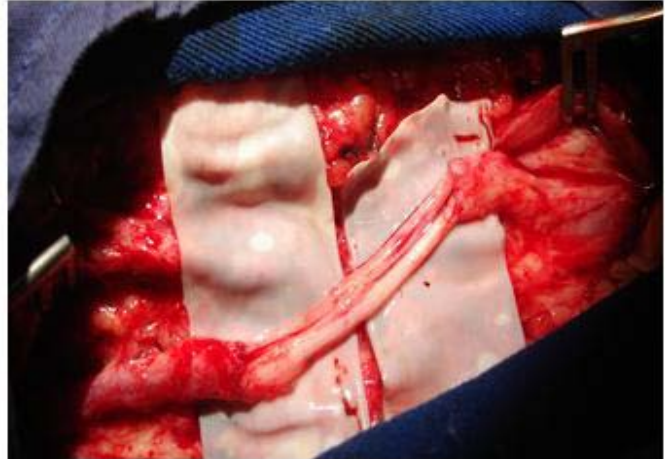

Figure 3: A 39-year-old patient, victim of motorcycle accident, was referred to our institution 9 months after trauma, with complete loss of strength in his right foot (grade 0). Electroneuromyography showed traumatic neuropathy of the peroneal joint with axonotmesis. He underwent grafting ( 2 grafts of 3 $\mathrm{cm}$ each) and evolved after 6 months with mild strength recovery (grade 1).

The existence of pain in the preoperative period was described in $42.86 \%$ of the cases (6/14), $75 \%$ (3/4) among women and $30 \%$ (3/10) among men. Despite this, hyperesthesia or hypoesthesia was reported in $28.57 \%(4 / 14)$ and $35.71 \%(5 / 14)$ of cases, respectively. Among women, 50\% (2/4) presented hyperesthesia, whereas among men, 20\% (2/10) and 50\% (5/10), presented hyperesthesia and hypoesthesia, respectively.

After a 6-month follow-up, pain was reported only in one woman (7.17\%; 1/14); when sensitivity was assessed, $85.71 \%(12 / 14)$ were normal and hypoesthesia was described in two cases $(14.29 \% ; 2 / 14)$, including one patient of each sex.

Sex of the patient did not interfere in the time from symptom onset to surgery, preoperative strength, or strength 6 months after surgery ( $p>0.05$ ). However, when strength was compared in preoperatively and at the 6-month follow-up, an increase was observed for both female and male patients $(\mathrm{p}<0.05)$ (Table 6).

Regarding complications of the procedures, only one male patient $(7.14 \% ; 1 / 14)$ presented surgical site infection in the postoperative period.

\section{Discussion}

In our study, traumatic injury was the most common cause of peroneal nerve injury, accounting for $64.27 \%$ of cases. This is similar to some results described in the literature [8-10], but contrasts with a study from the University of Louisiana, in which $87 \%$ of injuries were traumatic [8]. Traumatic injury could be explained by the susceptibility of the peroneal nerve to tensile forces due to its location and internal anatomy [8].

The main cause of tumoral lesions was ganglion cyst, corresponding to $21.43 \%$ of the cases, differing with that reported in the literature, of $40 \%$ [11]. The involvement of the peripheral nerves with ganglion cysts has been extensively studied and described in the literature, and multiple theories have been proposed, including cystic degeneration of neurilemmomas, expansion of synovial rests displaced during embryological development, herniation of joint synovium, and traumatic intraneural hemorrhage [12].

The lesion of the right common peroneal nerve was more common than that of the left (35.71\%), as found in the study by Terzis et al., in which $64 \%$ of the injuries occurred also on the right common peroneal nerve ( 40 of 62 patients) [1].

Regarding treatment, isolated neurolysis was the most performed 
procedure in our series, in $50 \%$ of the cases. This was similar to that reported in the study by Kim et al. [8], in which neurolysis was responsible for $38 \%$ of cases (121 patients out of a total of 318); and in the study by Terzis et al., in which $50 \%$ of the cases were treated with isolated micro neurolysis [1].

Repair, either by isolated graft or in conjunction with neurolysis, was performed in approximately $21 \%$ of our cases, compared with $43 \%$ [6] and $43.5 \%$ [1] in other studies. The graft sizes we used ranged from 5 to $8 \mathrm{~cm}$ and only one of three patients had partially recovered strength from grade 0 to grade 3 , whereas the others did not benefit from the treatment. It has been well established that the functional recovery of patients with grafts is more difficult, especially those with more extensive grafts. Patients with smaller grafts generally have better outcomes, because there is a direct correlation between graft length and severity of injury [8].

In our study, surgical treatment allowed improvement in strength in both sexes, with statistical relevance $(\mathrm{p}<0.05)$, as has also been shown in other centers $[8,9]$. Analysis of the patients with complete strength recovery after 6 months showed that $50 \%$ were approached within 3 months from symptom onset. The most accepted recommendation is that surgery should be performed as soon as possible on open injuries, but a delay of at least 3 months should be allowed on blunt injuries, due to the possibility of spontaneous recovery [1]. However, one of our patients, a victim of car accident, was approached within 2 months of injury, because he remained with significant loss of motor strength in the foot without any clinical or electroneuromyography improvement in that period of observation. $\mathrm{He}$ evolved in the postoperative period with complete strength recovery, showing that early surgery can be a therapeutic alternative in selected cases.

\section{Conclusions}

Our study has some limitations: it is a retrospective analysis, with a small number of patients treated in a single institution. We concluded that surgical exploration and repair of peroneal nerve injuries might improve patient outcomes. The goal of surgical treatment is to accomplish useful motor function. In selected cases, early treatment can be a therapeutic strategy.

\section{References}

1. Terzis JK, Kostas I. Outcomes with microsurgery of common peroneal nerve lesions. J Plast Reconstr Aesthet Surg. 2020; 73: 72-80.

2. Humphreys DB, Novak CB, Mackinnon SE. Patient outcome after common peroneal nerve decompression. J Neurosurg. 2007; 107: 314-318.

3. Wilson TJ, Maldonado AA, Amrami KK, Glazebrook KN, Moynagh MR, Spinner RJ. The anatomic location and importance of the tibialis posterior fascicular bundle at the sciatic nerve bifurcation: report of 3 cases. J Neurosurg. 2018; 131: 1869-1875.

4. Sunderland S. Nerve and Nerve injuries. $2^{\text {nd }}$ ed. New York: Churchill Livingstone. 1978: 967-999.

5. Kretschmer T, Antoniadis G, Braun V, Rath SA, Richter HP. Evaluation of iatrogenic lesions in 722 surgically treated cases of peripheral nerve trauma. J Neurosurg. 2001; 94: 905-912.

6. Robin F, Kuchenbuch M, Sauleau P, Marleix S, Lucas G, Fraisse B, et al. [Peroneal nerve palsy in children: Uncommon diagnosis of a proximal tibiofibular synovial cyst]. Arch Pediatr. 2016; 23: 90-93.

7. Heilbrun ME, Tsuruda JS, Townsend JJ, Heilbrun MP. Intraneural perineurioma of the common peroneal nerve. Case report and review of the literature. J Neurosurg. 2001; 94: 811-815.

8. Kim DH, Murovic JA, Tiel RL, Kline DG. Management and outcomes in 318 operative common peroneal nerve lesions at the Louisiana State University Health Sciences Center. Neurosurgery. 2004; 54: 1421-1428; discussion 1428-1429.

9. Thoma A, Fawcett S, Ginty M, Veltri K. Decompression of the common peroneal nerve: experience with 20 consecutive cases. Plast Reconstr Surg. 2001; 107: 1183-1189.

10. Banerjee T, Koons DD. Superficial peroneal nerve entrapment. Report of two cases. J Neurosurg. 1981; 55: 991-992.

11. Nucci F, Artico M, Santoro A, Bardella L, Delfini R, Bosco S, et al. Intraneural synovial cyst of the peroneal nerve: report of two cases and review of the literature. Neurosurgery. 1990; 26: 339-344.

12. Harbaugh KS, Tiel RL, Kline DG. Ganglion cyst involvement of periphera nerves. J Neurosurg. 1997; 87: 403-408. 